\title{
PROBLEMAS TEATRAIS NA EDUCAÇÃO ESCOLARIZADA: EXISTEM CONTEÚDOS EM TEATRO?
}

Este texto explora os desafios da tarefa de planejar e avaliar as práticas teatrais na educação escolarizada. Problematiza-se a ideia de conteúdos e propõe-se a reflexão sobre o conceito de noção por intermédio do qual o planejamento e a avaliação - como tecnologias educacionais de controle e performatização - poderiam ser resignificadas. Apresenta-se o contexto educacional no qual as noções teatrais podem ser propostas: a criação coletiva de alunos-atores e professores-diretores. Problematiza-se diferentes características das noções teatrais que implicam em atravessamentos discursivos e uma acepção de sujeito para além da ideia de um sujeito emancipado, uno e totalmente consciente de si.

Palavras-chave: teatro, pedagogia teatral, educação escolarizada, planejamento, avaliação.

This paper explores the challenges of planning and evaluating the theatre practices in school education. We problematise the idea of content and propose a reflection on the concept of sense through which the planning and evaluation - as educational technologies of control and performatization - could be resignified. We present the educational context in which theatrical notions can be proposed: collective creation of students-actors and teachersdirectors. We problematise different notions of theatrical features that imply discursive crossings and a sense of subject beyond the idea of an emancipated, unified and fully self-conscious subject.

Keywords: theatre, theatre pedagogy, school education, planning, evaluation. 


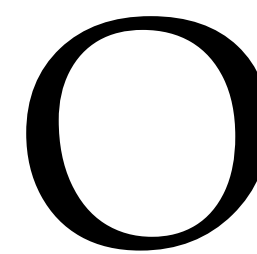
trabalho de orientação de estágios de docência em teatro, em escolas de ensino fundamental e médio, permite não apenas conhecer um pouco do cotidiano da educação escolarizada - e, como o teatro é praticado nesse contexto -, como também expõe algumas das dificuldades mais prementes enfrentadas pelos estagiários nas tarefas de ensinar. Tais dificuldades, no entanto, são percebidas pouco a pouco. Elas não são privilégio apenas dos alunos em formação, mas orbitam, também, no ambiente teatral da educação escolarizada como um todo - os professores de teatro em trabalho nas escolas, não raro, se deparam com desafios muito semelhantes.

As tarefas de planejar e avaliar estão, com efeito, no cerne desses problemas. Como se planeja uma aula de teatro? O que um currículo de teatro deve prever como conteúdos mínimos? Como avaliar os alunos? Existem conteúdos em teatro? Quais são os equivalentes teatrais dos conceitos científicos que os professores de outras áreas ensinam?

A eloquência de tais questões, a vastidão de problemas que elas aduzem e a complexidade do alcance que essas dúvidas denotam não permitem que se possa tratálos em conjunto neste trabalho, tampouco esses impasses pedagógicos são exclusivos do ensino de teatro.

Assim, por hora, esse texto irá se ocupar do problema dos conteúdos e como tal enunciado não pode alcançar os fenômenos criativos de que se ocupa o teatro. Esse texto, propositivamente, irá discutir o conceito de noção como forma por intermédio da qual o planejamento -

1 Gilberto Icle é ator e diretor de teatro. É graduado em artes cênicas, mestre e doutor em educação pela Universidade Federal do Rio Grande do Sul, na qual é professor no Programa de Pós-graduação em Educação e coordenador do GETEPE Grupo de estudos em educação, teatro e performance, do qual faz parte o grupo de teatro UTA-Usina do Trabalho do Ator. É autor de diversos artigos no país e exterior, além de livros como Teatro e construção de conhecimento, pela Editora Mercado Aberto; $O$ ator como xamã, pela Editora Perspectiva; Pedagogia teatral como cuidado de si, pela Editora Hucitec. É, também, editor-chefe da Revista Brasileira de Estudos da Presença. para além de um dispositivo de controle - poderia ser uma tecnologia educacional re-significada.

Desde que o teatro se efetivou como componente curricular obrigatório (e, de fato, esse processo sequer ganhou corpo no Brasil, sendo ainda incipiente) na educação escolarizada no nosso país, um sem número de friç̧ões ruidosas não deixam de ser sentidas nos usos que tal arte pode ter na escola.

A educação escolarizada institucionalizouse e operou com força total o seu projeto moderno de educação para todos a partir do momento em que as nações ocidentais começaram a se formar e se solidificar. Nesse contexto histórico, a industrialização acelerada exigiu uma escola de massa e, ao mesmo tempo, engendrou dispositivos capazes de circunscrever os elementos necessários para a formação e manutenção de uma sociedade disciplinar. O disciplinamento se fez perceber em instituições um tanto quanto similares do ponto de vista discursivo, tais como: a escola, a prisão, o manicômio, o hospital. É correto, pois, afirmar que "as disciplinas existiam há muito tempo" (FOUCAULT, 1979, p.105), os mosteiros do medievo são exemplos desse tipo de organização, mas a Escola de massa e as demais instituições da mesma ordem se organizaram nos séculos XVII e XVIII, "quando o poder disciplinar foi aperfeiçoado como uma nova técnica de gestão dos homens" (FOUCAULT, 1979, p.105).

Parece notório que nesse contexto de controle - no qual o saber foi correlato e par inseparável do poder (compreendido para além do modelo hegeliano de uma dialética como uma profusão de micropoderes) as disciplinas tiveram um papel fundante, pois "disciplinarizar é tanto organizar e classificar as ciências, quanto domesticar os corpos e as vontades" (GALLO, 2004, p.82). O teatro, contudo, por mais institucionalizado e representante da vida burguesa que possa ser, guardaria (essa é nossa esperança como educadores) um laivo de potência dionisíaca: tendência que levaria a uma desestabilização do dado, do idêntico, 
da regra; haveria na atividade teatral, portanto, algo de transgressor, uma alternativa à disciplina.

Não foi, consequentemente, sem litígio que o teatro ingressou no contexto da educação escolarizada, produzindo ao menos dois efeitos: o primeiro relacionado à desconfiança indagadora sobre a pertinência ou não de uma atividade tão livre: poderia ela trazer benefícios para a aprendizagem? Foi preciso o estabelecimento do discurso da Escola Nova, no início do século $X X$, para uma justificação mais elaborada da presença do teatro na escola (PAGE, 2009, p.28). E, o segundo, como consequência do primeiro, tratou de uma adaptação das atividades teatrais às rotinas da escola e às tecnologias escolares, inclusive aos procedimentos burocráticos impostos institucionalmente.

Assim, não é de estranhar que a tarefa de planejar a aula de teatro seja vista como um modo de controle, como um aparelho por intermédio do qual o professor é assujeitado e conformado à norma. Seria possível re-significar o ato de planejar e torná-lo uma tecnologia produtiva ao trabalho do professor de teatro?

Planejar não é, de qualquer forma, a salvação de todos os males e a saída para todos os impasses. Bem planejar não é, necessariamente, sinônimo de educação de qualidade. O planejar é apenas uma companhia com a qual o professor pode contar no sentido de refletir sobre e melhor re-dirigir as práticas desenvolvidas. Trata-se, com efeito, de uma tecnologia performativa.

Isso significa dizer que o planejamento, como tecnologia de dar forma à tarefa de ensinar, performatiza os sujeitos partícipes, forma e conforma os espaços, os tempos e as práticas escolares. Planejar tem, ao menos, duas dimensões: uma macro, queserefere às políticas públicas e governamentais para a educação; e, outra, micro, que se circunscreve no "nível escolar e de ensino" (CORAZZA, 2005, p.114). Nessa esfera micro estão contempladas as formas institucionais de currículo (o currículo da escola ou as previsões de conteúdos e atividades de um componente curricular, além dos planos político-pedagógicos) e as práticas de ensino (representadas e previstas pelos planos de curso, pelos planos de aula, pelos planos de disciplinas).

Embora diretrizes e políticas sejam formas abertas de planejar a educação, elas, com efeito, implicam em performatividades curriculares. Essas performatividades nos convocam a sermos e fazermos determinadas performances, ou seja, a desempenharmos determinados papéis na escola e a cumprirmos determinadas regras. Essas regras são controladas por uma complexa sequência de avaliações que tem se multiplicado no Brasil nos últimos anos: avaliações de desempenho dos alunos, das escolas, dos professores, assim como inspeções escolares das mais variadas. Assim, tecnologias como planos e avaliações institucionais não deixam de ser sempre modos de controle, sendo que nós mesmo nos performatizamos em tais tecnologias na medida em que elas "servem como medida de produtividade ou resultados, como formas de apresentação da qualidade ou momentos de promoção ou inspeção" (BALL, 2010, p.38).

Mas existiria alguma potência criativa nessas tecnologias do planejar, para além de fabricações performativas. Haveria performances criativas, invenções e produção de saberes teatrais em tais técnicas?

Ainda que de modo bastante hesitante, esforçar-me-ei em mostrar que, para além da dimensão da fabricação de aparências, pode existir algo de produtivo para a criação teatral na tarefa de planejar, desde que se possa olhar tal tarefa sob outros pontos de vista. Nesse sentido, é preciso iniciar pela suspensão do conceito de conteúdos e mesmo substituí-lo. Essa é a intenção a partir daqui.

\section{O conceito operacional de noção}

Parece desnecessário dizer que a emergência da necessidade de conteúdos na educação escolarizada remonta ao aparecimento da escola de massa. Qual são os conteúdos necessários para que todos tenham um conhecimento mínimo 
do que a humanidade produziu de justo e bom? Consequentemente, a seleção desses conteúdos diz sobre as relações de saber/poder em que eles estão enleados. Há, portanto, lutas para determinar quais são os saberes que devem ser professados e ensinados pela escola e quais desses estão hierarquicamente abaixo da linha que divide o que pertence e o que não pertence à Escola.

É notório, também, que a ideia de conteúdo aduz ao seu conceito correlato, o de forma, e foi no interior desse tipo de pensamento dialético que o par conteúdo/ forma emergiu e foi tomado como verdadeiro. Ora, o que se propõe aqui seria justamente desfazer o dualismo e, ao mesmo tempo, evidenciar que a separação entre forma e conteúdo não é senão uma falácia, na medida em que separa elementos impensáveis de serem separados.

A tarefa mais primitiva das tecnologias de planejamento escolar foi sempre a de listar conteúdos e programar os seus tempos e espaços de ocorrência. Agregado a isso, as visões mais tecnicistas enfatizavam o método segundo o qual tais conteúdos seriam transferidos aos alunos num tempo e num espaço suficiente para o aprendizado.

Nas ciências, a partição dos saberes, a distribuição das disciplinas, tantas vezes discutida pela filosofia contemporânea, não deixa de ser uma construção, não tendo nada de natural ou orgânico. A crença num mundo objetivo a ser descoberto pelo homem possibilitou, de fato, o nascimento das ciências sociais: o próprio homem passa a ser o objeto de sua busca (FOUCAULT, 1999). E a semelhança entre as coisas e as palavras que havia sustentado a epistéme clássica se rompe na modernidade dos séculos XVII e XVIII; não obstante, tem marcha a partir daí uma busca desenfreada por ordenar e classificar o mundo (FOUCAULT, 1999). É nesse caldo epistemológico que a ideia de conteúdos assume um papel preponderante na educação escolarizada, sobretudo a partir do século XIX.
Mas se a ideia de conteúdos é questionável e relativa no mundo das ciências, ela é ainda mais efêmera no mundo das artes. O que seriam conteúdos em teatro? O tema do espetáculo? A mensagem do texto? Os assuntos das ciências aplicados à cena teatral? Os elementos da linguagem teatral? Uma análise de sobrevôo em currículos e planos de ensino mostra um número infinito de palavras soltas e enunciações vazias: o corpo no espaço; expressão corporal; técnica vocal; improvisação; corpo; jogo; estado de jogo; foco; atenção; concentração. O que significam essas palavras na prática teatral?

Muitas dessas palavras não significam e não operacionalizam a prática teatral na educação escolarizada. Muitos alunos em formação e professores atuantes de teatro não sabem explicar como elas se traduzem em ação, que saberes elas podem efetivar e que modos de avaliação elas poderiam implicar. Em alguns casos, não sabem distinguir o que delas resta como conteúdo e o que delas se aplica como método.

Em função desse quadro complexo e nem sempre apaziguado da prática, eu proponho discutir aqui um conceito operacional para a prática teatral na educação escolarizada: o conceito de noção.

O que é uma noção teatral?

Antesdeelencaralgumascaracterísticas, será conveniente lembrar o contexto de sua aplicação. As noções atravessam o trabalho criativo da cena teatral. Isso significa dizer que se trata de um coletivo (de alunosatores e professor-diretor, mesmo que essas funções possam variar) empenhado em criar uma performance.

Muitas vezes necessitamos realizar tarefas em sala de aula que não estão diretamente relacionadas com o cerne da atividade teatral, mas são preparatórias ou requisitos para que o objetivo principal possa se desenvolver. Assim, um aquecimento, como forma de iniciar uma oficina, pode ou não introduzir aos participantes uma noção teatral. Ele pode apenas prepará-los, dar condições deinício, 
concentrar os alunos. Uma conversa ou uma avaliação sobre problemas e barreiras que impedem o bom funcionamento da oficina não indicam necessariamente palestras ou exposições sobre uma noção teatral. Elas podem intervir apenas no funcionamento da oficina como, por exemplo, impedir que os alunos sigam sem esclarecimento de determinado assunto ou sem uma discussão sobre algum aspecto do relacionamento pessoal.

Uma noção teatral, portanto, irrompeno contexto da criação de espetáculos - mesmo que eles não tenham o objetivo direto de ir a público externo -, da criação de cenas em oficinas e na criação de improvisações ou performances e outros dispositivos que possamos nomear como espetáculo vivo, ainda que restrito à experiência da própria sala de aula. Esses contextos são tão amplos quanto às modalidades de improvisação e composição teatral como jogos dramáticos, jogos teatrais, drama, dramatização; enão se restringem à educação escolarizada. Todas as formas de criação teatral trabalham com a construção de noções.

Uma noção não se localiza nem na prática, tampouco na teoria teatral. Ela está mais ou menos aparente num entre-lugar da prática e da teoria. Nós não podemos encontrar as noções prontas nas teorias teatrais, embora indícios das noções habitem os textos de teóricos e artistas da cena. Podemos encontrar um indício da noção de irradiação no texto de Michael Chekhov (1986) ou indícios das noções de contar/ mostrar em Viola Spolin (1986). A irradiação, por exemplo, não existe como algo dado, precisamos que um grupo de pessoas a experimente, precisamos nos sujeitar a ela e ao mesmo tempo sermos sujeitos dela. É necessário recriá-la no corpo para que ela exista. Trata-se de imaginar que as noções não estão por aí, no mundo, esperando que nós as descubramos; elas precisam ser praticadas, tornadas corpo, experienciadas. Indícios das noções podem ser encontrados nos escritos, mas diferentemente dos conceitos científicos, as noções não tem existência senão na efemeridade da prática.
As noções são ao mesmo tempo privadas e coletivas. Elas são privadas, pois requerem um corpo e movimento em vida para existirem e são coletivas por que a natureza mesma de sua existência coincide com aquela do teatro; as noções vivem na relação com o outro. Não existe uma noção teatral que não seja ao mesmo tempo efêmera (sua forma se desfaz na própria existência) e compartilhada (é necessário alguém que seja um espelho da noção, alguém que olhe para o corpo em vida que experiência a noção).

Ela se forma, portanto, no entre-lugar da palavra. Nós podemos falar da noção e falar constrói as noções, mas a palavra não é espaço suficiente para a existência das noções. É preciso viver uma noção no corpo, embora possamos explicá-la, traduzi-la em palavras, discuti-la, re-significá-la.

As noções são sempre provisórias. Elas são operacionais, ou seja, elas existem como instrumentos de criação e precisam ser re-atualizadas a cada momento. Assim, para um grupo de alunos-atores iniciantes, talvez seja conveniente trabalhar a noção de estar em cena e de estar fora de cena. Depois que um conjunto de atividades tenha sido experenciado para que eles experimentem com o corpo a sensação de estar em cena e a diferença de seu próprio corpo fora de cena - e que experimentem também procurar olhar no corpo dos colegas essa mesma diferenciação - é provável que essa noção não seja mais necessária e tenhamos que passar a outras mais complexas.

As noções, ainda, criam vocabulário próprio para o grupo que trabalha junto, pois a mesma noção, por exemplo, estar em cena e estar fora de cena, pode ser nomeada com outro vocabulário, dentro e fora, sobre o tapete e fora dele, em ação e no cotidiano, presente e não presente; esse modo de falar depende é claro da comunidade de fala a que pertence o grupo, da faixa etária, do lugar de enunciação donde a noção provem, do tipo de relação que o professor estabelece com os alunos e da sua inventividade em nomear e ser compreendido pelos alunos-atores. 
Substituir os conteúdos por noções implica compreender que as noções teatrais não são temas de trabalho e muito menos os antigos temas geradores. Assim, o amor, o poder, o envelhecimento, o respeito ao próximo, o trânsito não são noções teatrais, ainda que não possamos dispensar algumas delas em função da vida que pulsa na sala de aula, da mesma forma que não deixamos de trabalhar com os grandes temas da literatura e do espetáculo, mas esses podem ser mediados com os alunos, a partir de seus interesses, de suas preocupações. Trabalhar com noções teatrais não significa dizer trabalhar no vazio da forma, os temas e assuntos continuam lá no interior funcional da cena, mas não é sobre eles que as noções se constroem, tampouco separadas deles que elas se engendram.

Noções teatrais possuem uma medida de concretude, assim, vocabulários demasiadamente abertos, como criatividade, imaginação, emoção, não são desejáveis para operarem como noções teatrais. Eles implicam dificuldades de avaliação, pois não sabemos exatamente do que se trata, tampouco podemos apontar aos alunosatores que assistem o exercício o quando isso ocorre na cena que observamos. As noções teatrais precisam ser facilmente identificáveis. Elas aduzem a elementos corporais concretos. Mesmo noções complexas como as de tempo-ritmo podem ser detectadas em cena por um olhar apurado.

A dimensão criativa é própria das noções teatrais, nelas estão possibilitados espaços de resolução de problemas concretos para os quais não existe uma resposta correta, mais uma multiplicidade de possibilidades. É por isso que as noções teatrais não são conceitos científicos, elas não possuem uma previsibilidade, elas são dependentes do contexto de emergência no qual elas se constituem.

Como elas implicam a construção de um vocabulário particular pelo grupo em trabalho, elas fornecem os mecanismos para a avaliação. Perguntas simples servem como construtoras das noções e ao mesmo tempo como avaliações do percurso realizado e dos caminhos a serem perseguidos em seguida. Vejamos a noção de estar em cena e estar fora de cena. Podemos perguntar aos alunos-atores qual é a diferença, mas podemos, também, solicitar que apontem no trabalho cênico dos colegas quando essa noção é mais evidente e quando ela não pode ser percebida.

Esse jogo entre fazer e falar, fazer e observar, fazer e refletir, constitui as noções teatrais. É evidente que as noções teatrais possuem nesse jogo uma tendência ao lúdico, mas não necessariamente elas se constituem em atividades lúdicas, pois, em muitos casos, a repetição, a composição detalhada e outros artifícios da carpintaria teatral requerem um trabalho menos interessante e mais aborrecido de preparação, para somente num segundo momento restabelecer o elo de ligação com a ludicidade.

Tomar a tarefa de planejar a partir do conceito operacional de noção significa, por sua vez, trabalhar com uma acepção específica de sujeito.

As noções teatrais desmancham a ideia de um sujeito soberano e racional. Não há lugar para "algo como o núcleo essencial de subjetividade que pode ser pedagogicamente manipulado para fazer surgir o seu avatar crítico na figura do sujeito que vê a si próprio e à sociedade [...], adquirindo, no processo, a capacidade de contribuir para transformá-la" (SILVA, 2000, p.13). Se as noções não são conteúdos a serem aprendidos, se elas precisam ser criadas a partir de um quadro discursivo que as legitima, visto que têm origem sempre num determinado modo de falar sobre o teatro (posso escolher o modo de Stanislavski, de Copeau, de Barba, de Boal ou de qualquer outro como ponto de partida), elas são exterioridades que permanecem num vazio de consciência.

As noções teatrais existem tanto no corpo como fenômeno, quanto na linguagem como modo de falar, no entanto, essa expressão da linguagem não guarda em si um significado escondido, guardado na subjetividade do indivíduo, elas 
produzem linguagem e são produzidas por ela. O centro da produção das noções teatrais não é um sujeito centrado, mas partido, alguém que ocupa um lugar por um momento e o deixa tão vazio quanto ele já estava antes de ter sido ocupado. As noções teatrais, da forma aqui abordada, supõem um jogo da linguagem, elas lembram que os significados são constantemente renegociados coletivamente (DERRIDA, 1967).

Nesse jogo sem fim, a tarefa do professor-diretor não poderá ser outra senão criar juntamente com os alunosatores. Desfaz-se, assim, as hierarquias mais rígidas, todos são criadores e a tarefa coletiva do teatro na educação escolarizada podeser circunscrita no dever de multiplicar as noções. As noções nunca cabem em si mesmas, elas necessitam sempre o trabalho de noções correlatas, derivadas ou opostas. Elas têm vocação a se multiplicar: cria-se uma noção a partir de outra. E o que nos restaria, a nós professores de teatro, senão multiplicar as noções teatrais?

\section{Referências bibliográficas}

BALL, Sthephen J. Performatividades e fabricações na economia educacional: rumo a uma sociedade performativa. Educação $\mathcal{E}$ Realidade. Porto Alegre: UFRGS, v.35, n.2, 2010, p. 37-55.

CHEKHOV, Michael. Para o ator. São Paulo: Martins Fontes, 1986.

DERRIDA, Jacques. L'écriture et la différence. Paris: Éditions du Seuil, 1967.

FOUCAULT, Michel. As palavras e as coisas. São Paulo: Martins Fontes, 1999.

FOUCAULT, Michel. Microfísica do poder. Rio de Janeiro: Graal, 1979.

GALLO, Silvio. Repensar a educação: Foucault. Educação \& Realidade. Porto Alegre: UFRGS, v.29, n.1, jan/jun.2004, p.79-97.

PAGE, Christiane. Pratiques théâtrales dans l'éducation en France au XXe siècle: aliénation ou émancipation? Arras: Artois Presses Université, 2009.
SILVA, Tomaz Tadeu da (Org.). Pedagogia dos monstros: os prazeres e os perigos da confusão de fronteiras. Belo Horizonte: Autêntica, 2000.

SPOLIN, Viola. Improvisação para o teatro. São Paulo: Perspectiva, 1986. 